Research Paper

\title{
Inhibition of human amylin aggregation by Flavonoid Chrysin: An in-silico and in-vitro approach
}

\author{
Abdullah A. Alkahtane ${ }^{1}$, Hamzah A. Alghamdi ${ }^{1}$, Bader Almutairi ${ }^{1}$, Mohd Muazzam Khan², Md Saquib \\ Hasnain³, Mohamed M. Abdel-Daim ${ }^{1,4}$, Wadha M. Alghamdi5 ${ }^{5}$ Saad Alkahtani ${ }^{\circledR}$ \\ 1. Department of Zoology, College of Science, King Saud University, Riyadh, Saudi Arabia. \\ 2. Department of Pharmacology, Faculty of Pharmacy, Integral University, Lucknow, India. \\ 3. Department of Pharmacy, Shri Venkateshwara University, NH-24, Rajabpur, Gajraula, Amroha - 244236, U.P., India. \\ 4. Pharmacology Department, Faculty of Veterinary Medicine, Suez Canal University, Ismailia 41522, Egypt. \\ 5. Medical Services at the Ministry of Interior, Riyadh, Saudi Arabia. \\ $\square$ Corresponding author: Prof. Saad Alkahtani, Department of Zoology, College of Science, King Saud University, P.O. Box 2455, Riyadh 11451, Saudi Arabia. \\ E-mail: salkahtani@ksu.edu.sa. \\ (c) The author(s). This is an open access article distributed under the terms of the Creative Commons Attribution License (https://creativecommons.org/licenses/by/4.0/). \\ See http://ivyspring.com/terms for full terms and conditions.
}

Received: 2020.08.01; Accepted: 2020.10.16; Published: 2021.01.01

\begin{abstract}
Islet amyloid polypeptide (amylin), consecrated by the pancreatic $\beta$-cells with insulin, has a significant role to play in maintaining homeostasis of islet cell hormones. Alzheimer's disease is the predominant source of dementia. However, its etiology remains uncertain; it appears that type 2 diabetes mellitus and other prediabetic states of insulin resistance contribute to the intermittent Alzheimer's disease presence. Amylin is abnormally elevated in Type II diabetes patients, accumulated into amylin aggregates, and ultimately causes apoptosis of the $\beta$-cells, and till date, its mechanism remains unclear. Several flavonoids have inhibitory effects on amylin amyloidosis, but its inhibition mechanisms are unknown. Screening a collection of traditional compounds revealed the flavone Chrysin, a potential lead compound. Chrysin inhibits amyloid aggregate formation according to Thioflavin $T$ binding, turbidimetry assay. We report results of molecular interaction analysis of Chrysin with amylin which shows potent binding affinity against amylin. Pharmacokinetics and Drug likeness studies of Chrysin also suggest that it is a potential lead compound. Therefore, Chrysin prevented amylin aggregation.
\end{abstract}

Key words: Islet amyloid polypeptide, Chrysin, flavonoids, amylin aggregation

\section{Introduction}

According to a large number of studies, there is a strong association between genetic mutations, proteins dysfunction, environmental factors and neurodegenerative disorders [1]. More evidence from epidemiological investigations, animal experiments, and ex vivo cell experiments showed that exposure to particulate matter (PM) may lead to neuroinflammation, oxidative stress, mitochondrial dysfunction, neuronal apoptosis, synaptic damage and ultimately neurodegenerative diseases [2,3]. Aberrant misfolding of proteins, as well as peptides into insoluble fibrils and aggregates, has indeed been related to multiple abnormalities such as Alzheimer's disease, Parkinson's disease, and type 2 diabetes mellitus (T2DM) [4]. Amylin is a hormone of 37 amino acids long-chain, co-secreted with insulin from secretory pancreatic $\beta$-cell granules. Under T2DMrelated hyperglycemic conditions, islet amyloid polypeptide (amylin) is susceptible to form oligomeric species and amyloidogenic aggregates that have been described to mediate dysfunction and apoptosis in pancreatic $\beta$-cells that secrete insulin and have been linked to insulin insufficiency in T2DM subjects [5-8].

Type 2 diabetes affects about 25.8 million Americans (about 8.3 percent of the population with almost 2 million new cases annually [9]. Although the primary causes of type 2 diabetes remain uncertain, and the development of protein aggregates of the amyloid protein amylin is one of the factors leading to the progression of this disorder. These aggregates are potentially toxic to mammalian cells, in particular, the insulin-producing pancreatic $\beta$-cells [10]. The 
prevention and the production of amylin is believed to slow, if not effectively stop, the progression of type 2 diabetes [11].

Alzheimer's disease is the leading neurological disorder in human beings, causing dementia, and so far, no drug or treatment has been found for the disease. Amylin aggregates are characteristic of several neurological disorders, which include diseases of such Alzheimer's, Huntington's and Parkinson's [4]. Alzheimer's disease is a progressive form of dementia in postmortem brain tissues that is associated with neurofibrillary tangles and neurite plaques. These plaques contain extracellular aggregates of amyloid beta peptides whilst tangles are formed by intraneuronal accumulation of insoluble and hyperphosphorylated tau protein $[12,13]$. Some research emphasized soluble amyloid- $\beta$ oligomers as the primary toxic species in Alzheimer's disease [14]. Different approaches were predicted to recognize inhibitors of amylin protein folding and aggregation, based on the above evidences, and to prevent or treat Alzheimer's disease. Examples include the use of small peptides (such as $\beta$-sheet blockers), [15-17], the use of agents that decrease amylin production $[14,18]$, ways to increase amyloid- $\beta$ clearance (amyloid vaccine) $[19,20]$, and use of anti-oxidants $[21,22]$.

The disease is exemplified by extracellular markers of amylin fibrils, hyperphosphorylated and misfolded tau protein intracellular neurofibrillary tangles, vascular injury inevitably results from substantial plaque accumulation and the deterioration of neuronal cells and synapses [23]. Based on the most recent prominent hypothesis of neurodegenerative diseases, amyloid cascade, i.e., the deposition of amyloid- $\beta$ peptide into plaques in brain tissue is the diseases causative agent [24]. Produced from a singlepass transmembrane protein, amyloid precursor protein, amyloid- $\beta$ is an amphiphilic and partially folded molecule, prone to self-aggregation, producing intermediate oligomers or protofibrils and ultimately insoluble fibrils [25]. Amyloid- $\beta$ impairs the functioning of certain membrane carriers, enhances cellular oxidative stress, and triggers neuroinflammation, resulting in substantial synapse dysfunction and loss of neurons $[25,26]$.

It is known that at the molecular level, the naturally occurring plant ingredients exhibit a variety of functions as well as medicinally useful activities. Vegetables, spices, and herbal extracts have been reported as having beneficial health practices. The essential organic compounds in herbs, spices, and vegetables were studied for their antioxidant, antitumor, and anti-aging properties $[9,27,28]$. Flavonoids are present in many plants, fruits, and vegetables and are considered as one of the most natural phyto- chemicals with a variety of pharmacological activities $[29,30]$. These secondary metabolites were identified as potent antioxidants, free radical scavengers, and metal chelators [31-34] with anti-inflammatory $[33,35]$, anticholinesterase [36] and neuroprotective properties $[37,38]$. Besides, flavonoids can cross the blood-brain barrier with chronic or acute administration, indicating that these molecules could have a positive effect on the brain so that they can be used as prophylactics to delay the development of diseases like Alzheimer's as well as Parkinson's disease [39]. Chrysin is a flavonoid that has drawn significant interest to its advantages in various conditions, which include neurodegenerative diseases, due to its numerous signaling pathways [40,41]. Many reports highlighted the importance of flavonoids in neurodegenerative diseases [42-44]. Therefore in the present study, we have reported the in-vitro activity of flavonoid Chrysin on the inhibitory potential of amyloid aggregation.

\section{Material and methods}

\section{Chemicals/reagents}

Chrysin (5,7-Dihydroxyflavone), Amylin, Congo red, Thioflavin $\mathrm{T}$ was purchased from Sigma-Aldrich, Inc. St Louis, MO, USA.

\section{Ligand Preparation}

For computational simulation three dimensional (3D) structure of ligand molecule, Chrysin was retrieved from the PubChem database. Chrysin with PubChem ID (CID: 5281607) was used here for molecular interaction.

\section{Receptor Identification and Preparation}

The human amylin structure was obtained from the Research collaborator for structural bioinformatics (RCSB) Protein data bank with PDB ID: 2L86 containing NMR structure. This PDB entry selected as it presents amylin in its native amidated form at physiological $\mathrm{pH}$ [45]. Energy minimization of the fibril was done by the software Swiss PDB viewer 4.0.4.

\section{Molecular Docking Studies}

A molecular docking study was performed to identify the binding pattern between flavonoid chrysin and hIAPP by using the software Autodock 4.2. Lamarckian genetic algorithm methodology was employed for docking simulations implemented in AutoDock 4.2 [46]. Here, 100 docking models are generated to search for the best interaction pattern of Chrysin towards the hIAPP. Using the AutoDock tools essential hydrogen atoms, Kollman united atom type charges, and solvation parameters were added. 
Affinity (grid) maps in $x, y$ and $z$ coordinates were set as $60 \times 60 \times 60 \AA$ grid points and $0.375 \AA$ spacing were generated using the autogrid program aimed to target grid co-ordinates inactive pocket of amylin fibril. Docking simulations were performed using the Lamarckian genetic algorithm (LGA) and the 'Solis \& Wets local search method'. The population size was set to 150. The final figure was generated with the help of Discovery Studio Visualizer (Accelrys).

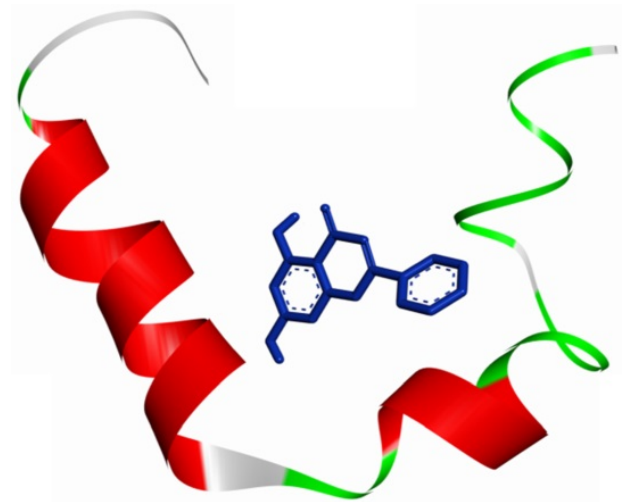

Figure 1. An overall view of the molecular docking pose of Chrysin into the binding site of hIAPP. Chrysin interact in the active pocket of amylin (human islet amyloid polypeptide).

\section{Turbidity assay}

Turbidity analyses were used to detect high-throughput screening false positives. To this, 50 $\mu \mathrm{M}$ amylin was mixed with $100 \mu \mathrm{M}$ of the test compound. The kinetics of aggregation was monitored at an absorbance of $360 \mathrm{~nm}$ every $30 \mathrm{~min}$ using a Plate reader $[47,48]$.

\section{Cell culture}

C6, a rat glioma cell line, was procured from American Type Culture Collection (Manassas, VA, USA). The cells were cultured in tissue culture flasks and grown in Ham's F12 medium (Sigma Aldrich) supplemented with 10\% Fetal bovine serum (FBS; Gibco, New Zealand), and 1\% antibiotic antimycotic solution (Sigma-Aldrich) in a humidified atmosphere of air and $5 \% \mathrm{CO} 2$ at $37^{\circ} \mathrm{C}$.

\section{Cytotoxicity assays}

The in-vitro cytotoxicity of naringin was determined following the protocol by 3-(4,5-Dimethylthiazol-2-yl)-2,5-Diphenyltetrazolium bromide (MTT) (Sigma-Aldrich) assay [49]. Briefly, in 96 well plates, C6 cells were seeded and incubated for 24 hours. Semi-confluent cells have been exposed to increasing chrysin concentrations for $24 \mathrm{~h}$. Cells were added per well with $10 \mu \mathrm{l}$ of MTT solution for MTT analysis and incubated at $37^{\circ} \mathrm{C}$ for $4 \mathrm{~h}$. $100 \mu \mathrm{l}$ of solubilization solution was applied to each well after incubation and well mixed to dissolve formazan crystals. Absorption was taken with a microplate reader at $570 \mathrm{~nm}$. The IC50 of Chrysin was found to be $71.237 \mu \mathrm{M}$.

\section{Thioflavin T fluorescence measurement}

C6 cells were maintained in DMEM supplemented with $5 \mathrm{mM}$ D-glucose, 10\% FBS, and $1 \%$ antibiotic/antimycotic solution in a humidified atmosphere of air and $5 \% \mathrm{CO} 2$ at $37^{\circ} \mathrm{C}$. C 6 cells were subjected to the treatment of amylin $(25 \mathrm{nM})$ with or without chrysin $(50 \mu \mathrm{M})$ for 24 hours. Cells were washed with PBS and added Thioflavin T (ThT) dye (5 $\mu \mathrm{M})$. Fluorescence was determined at excitation and emission wavelengths $440 \mathrm{~nm}$ and $482 \mathrm{~nm}$ respectively.

\section{Congo red staining}

C6 cells were subjected to the treatment of amylin $(25 \mathrm{nM})$ with or without chrysin $(50 \mu \mathrm{M})$ for 24 hours. Cells were washed with PBS and added congo red dye. After incubation for half an hour, the image was taken under a fluorescent microscope EvosFLc Microscope (Thermo-Scientific).

\section{Data Analysis}

Results were expressed as Mean \pm SEM. Multiple data comparisons involving more than two groups and/or time points were analyzed by one-way ANOVA followed by Tukey's multiple comparisons tests using GraphPad Prism 7.0 software (GraphPad Software, San Diego, CA, USA). Data comparison involving two groups was analyzed using the two-tailed unpaired Student $t$-test. $p<0.05$ value was set as statistically significant.

\section{Results}

\section{Molecular Docking}

The molecular docking method was proposed for the visual identification of the binding pose of amylin with its inhibitor. Chrysin was found to interact in the active pocket of amylin the human islet amyloid polypeptide as shown clearly in figure 1 . Maximum binding affinity between amylin and chrysin was found to be $-6.45 \mathrm{Kcal} / \mathrm{mol}$ with $23.25 \mu \mathrm{M}$ Ki (inhibition constant) shown a strong interaction between the two as data shown in Table 1. Residues Arg11 and Asn14 were found to anchor the chrysin molecule at the active binding site of amylin. While it is predicted that residues Phe15, His18, Asn21, Asn22, Ala25, and Asn31 might help in the efficient interaction. Chrysin forms three strong H-bonds with the amylin respectively at the positions $\mathrm{O} 3$ of chrysin with Arg11 (position) of amylin with a bond length of $2.88 \AA$, at $\mathrm{O} 4$ of chrysin with Asn14 of amylin with a bond length of $2.19 \AA$ and at OD1 of chrysin with 
UNK0 position of amylin with a bond length of 2.13 as shown in Figure 2.

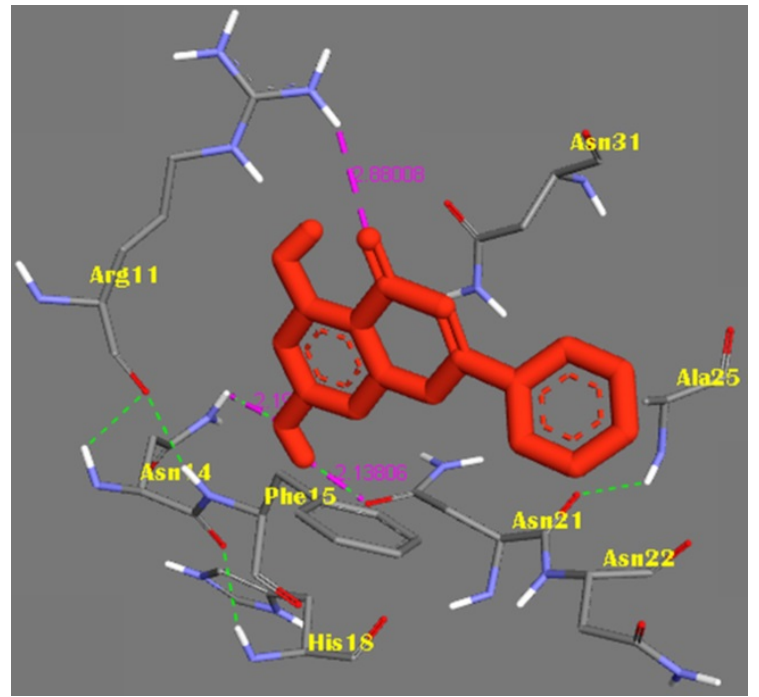

Figure 2. Representation of the binding mode between Chrysin and hIAPP. Chrysin molecule was represented by RED color; hIAPP was represented in BLUE-GREY stick representation surrounded the Chrysin by its active interacting amino acid residues in YELLOW. Hydrogen bonds were shown as GREEN dots. Intermolecular H-bonds were shown with their respective bond lengths in PINK.

\section{Effect of Chrysin on amylin aggregation}

In vitro, the amylin aggregation was determined by the turbidity assay technique. The amylin forms aggregate with an increase in time, as shown by the kinetic study performed. The test molecule Chrysin inhibited the aggregation fibril formation (Figure 3).

\section{Effect of Chrysin on amylin aggregation by ThT assay and congo red staining}

The ThT assay, as well as congo red staining, was performed in C6 cell lines. Cells exposed to amylin shows increased fluorescent intensity using dye ThT and enhanced amylin aggregation using Congo dye.
This increase in amylin aggregation was decreased by the treatment of Chrysin, as depicted in Figures 4 and 5.

\section{Discussion}

Since amylin is considered as the initiator of events leading to neurotoxicity and the clinical symptoms of Alzheimer's disease, the hunt for anti-amyloid therapies has become a significant strategy in Alzheimer's disease-related study [50-52]. The potential therapeutic approaches have been so far proposed to reduce the production of the amyloidogenic form of proteins, to increase the clearance rate of misfolded or aggregated proteins or to stabilize the native state of amyloidogenic proteins, as well as to directly inhibit the self-assembly process. At the moment, the focus is put on regulating the prefibrillar conformers (soluble oligomers) of amylin proteins, as these are typically the most toxic aggregates in vitro and in vivo [4,53-55]. Rather than targeting all possible intermolecular contacts, the use of small molecules such as sugars, polyols, amino acids, amines, salts, polymers and surfactants that interrupt specific intermolecular contacts could be a better way to alter the nucleation pathway and prevent the formation of fibrils. Flavonoid, strongly linked to quercetin, has already been identified as inhibiting the aggregation of amylin as well as disaggregating its fibres [55,57]. Quercetin prevents amylin aggregation and partially safeguards RIN-m5F cells from damage caused by extracellularly incorporated amylin [48]. There is growing interest in herbal medicine today, as they are also viewed favorably as more natural therapies than prescription drugs. In particular, successful dementia treatments have been developed from herbal medicines [58].

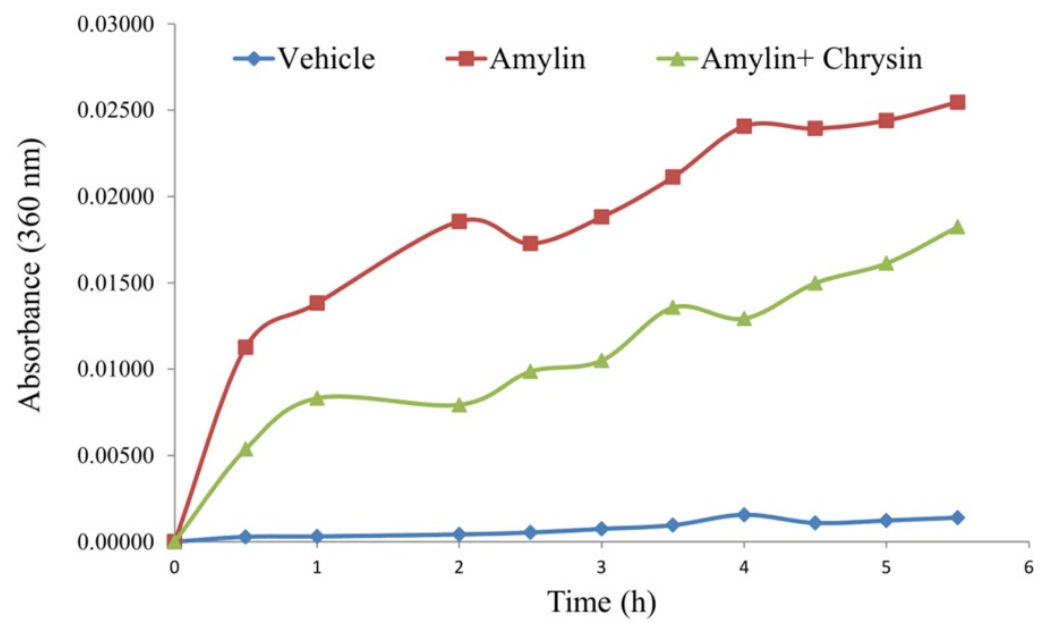

Figure 3. Effect of Chrysin on amylin aggregation measured at $360 \mathrm{~nm}$ for $5.5 \mathrm{~h}$. The amylin aggregation was determined by the turbidity assay technique. The amylin forms aggregate with an increase in time, as shown by the kinetic study performed. The test molecule Chrysin inhibited the aggregation fibril formation. 
Table 1. Binding affinity between amylin and chrysin

\begin{tabular}{|c|c|c|c|c|c|c|}
\hline Target & $\begin{array}{l}\text { Compound } \\
\text { Name }\end{array}$ & Binding Energy $(\Delta G)$ & $\begin{array}{l}\text { Inhibition } \\
\text { Constant Ki }\end{array}$ & Interacting Amino Acids & $\begin{array}{l}\text { No. of } \\
\text { H-bonds }\end{array}$ & $\begin{array}{l}\text { No. of intermolecular } \\
\text { H-bonds }\end{array}$ \\
\hline $\begin{array}{l}\text { Human islet amyloid } \\
\text { polypetide (amylin) }\end{array}$ & Chrysin & $-6.45 \mathrm{Kcal} / \mathrm{mol}$ & $23.25 \mu \mathrm{M}$ & $\begin{array}{l}\text { Arg11, Asn14, Phe15, His18, Asn21, Asn22, } \\
\text { Ala25, Asn31 }\end{array}$ & 9 & 3 \\
\hline
\end{tabular}

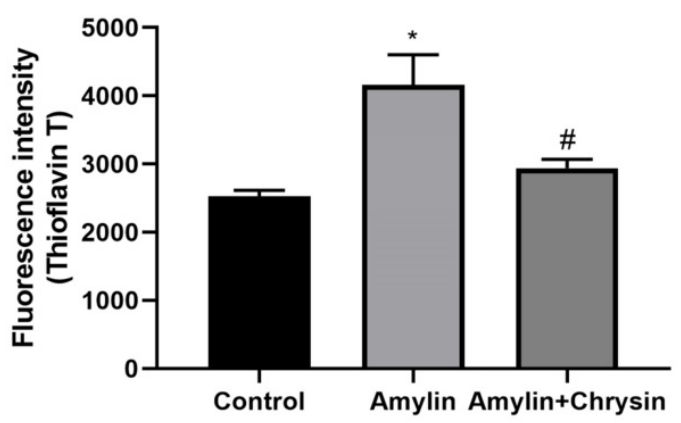

Figure 4. Effect of Chrysin on amylin aggregation by using Thioflavin T (ThT). Cells exposed to amylin shows increased fluorescent intensity. This increase in amylin aggregation was decreased by the treatment of Chrysin. The fluorescence intensity was measured at excitation and emission wavelengths $440 \mathrm{~nm}$ and $482 \mathrm{~nm}$.

Studies suggest that both anti-oxidative and anti-apoptotic properties of chrysin (especially in the dose of $100 \mathrm{mg} / \mathrm{kg}$ ) are possible mechanisms that improve cognitive/motor deficits and prevent neuronal cell death after traumatic brain injury [59]. This peptide has played a central role in Alzheimer's studies ever since exploration that perhaps the amylin peptide is the chief component of the fibrils present in the extraneuronal senile neuritic plaques in the brains of Alzheimer's patients. The soluble oligomers are now considered to be neurotoxic, and the mature fibrils of the amyloid beta-peptide are not per se neurotoxic. Some believe that the mature amylin fibrils may serve as a reservoir of amyloid betapeptide soluble oligomers. Thus, there seems to be scientific proof that, following oligomerization, huge aggregates may release smaller aggregates reversibly. After high-speed centrifugation of brain extracts, soluble amylin peptide oligomers are identified as what remains in aqueous solution.

Amyloidosis is correlated with the largest class of protein misfolding diseases which involves a wide range of neurological, metabolic, and agingassociated conditions including Alzheimer's disease, prion disease, Parkinson's disease, and type 2 diabetes diseases. The distinguishing pathological features of amylin are intracellular and extracellular insoluble protein deposits called amyloid fibrils [4,60,61]. The amylin fibrils are formed with time (Figure 3) and appear to be turbid. The aggregation of amylin proteins progresses through a nucleation-dependent cycle in which monomeric and oligomeric aggregates form "seeds" that induce a cascade of aggregation resulting in a balance between mature amyloid fibrils and their small precursor aggregates. Mature amyloid fibrils consist of several unbranched segments of the protofilament, which in turn are composed of $\beta$-sheet rich protein structures. Both structures stack each other, creating the conserved "cross beta spine" amyloid, distinguished by individual $\beta$-strand units perpendicular to the protofilament's long axis [4]. This formed amylin fibril or turbidity is inhibited by the addition of Chrysin, which shows that the flavonoid Chrysin inhibits the amylin fibril formation due to its antioxidant activity (Figure 3).

The formation of neurotoxic oligomers and protofibrils are the main steps leading to plaque formation in the central nervous system, which results in Alzheimer's disease neurodegeneration. Insoluble amylin oligomers and protofibrils have been shown to have a cytotoxic effect compared to soluble peptides when incubated with in vitro neuronal cells [62]. Besides, it was also shown previously that amylin induces the production of reactive oxygen species [63]. Based on these findings, amylin peptides are suggested as appropriate therapeutic targets in disease-like Alzheimer's disease that may have a disease-modifying effect. The amylin aggregation

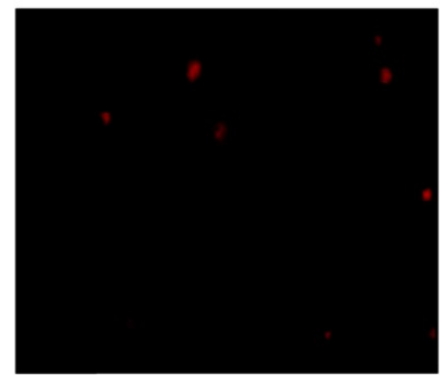

Control

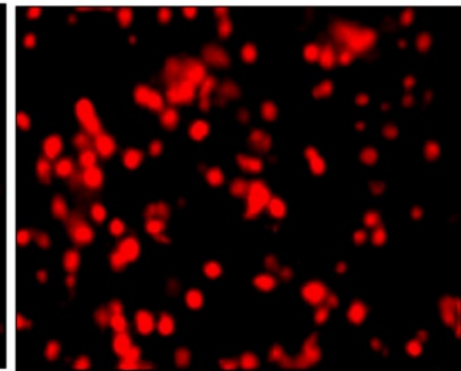

Amylin

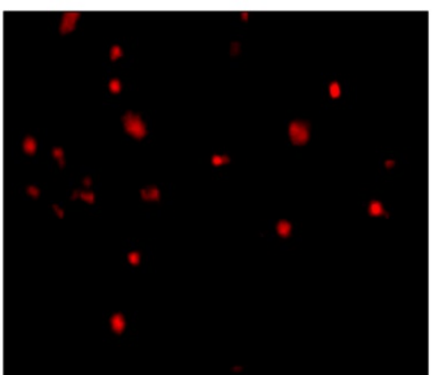

Amylin+Chrysin

Figure 5. Effect of Chrysin on amylin aggregation by using Congo red dye. Cells exposed to amylin shows enhanced amylin aggregation. This increase in amylin aggregation was decreased by the treatment of Chrysin. 
takes place as revealed by the Thioflavin $\mathrm{T}$ assay, the fluorescence intensity of the amylin treated group shows increased fluorescence intensity as compared to the control group $(p<0.05)$ (Figure 4). Simultaneously the congo red stained cells depicts enhanced intensity as compared to the control group, which reveals that amylin form aggregates in C6 glioma cells when treated with amylin (Figure 5). Thus on treatment with Chrysin, it inhibits the aggregate fibril formation and gives less fluorescence intensity with Thioflavin $\mathrm{T}(p<0.05)$ (Figure 4$)$ and produces a low intensity of fibril aggregates when treated with Chrysin in congo red binding assay (Figure 5). In regards to protein concentration, numerous factors may contribute to amyloidogenic aggregation, such as cellular environment and genetic mutations. For the pathologic amylin amyloid formation implicated in T2DM, no inhibitors have yet been clinically approved, making the prevention of amylin amyloid formation a very active area of research [64]. As with the potent inhibitors, chrysin, the amylin lag step extension, when incubated with inhibitor, indicates that inhibitors are likely to interfere with amylin protein at an early stage in the aggregation process to minimize amyloidogenic fibril formation. Chrysin can act on destabilized monomeric amylin and slow down the transition to larger oligomeric structures, which, in turn, are precursors to amylin amyloid fibrils. Chrysin reduces the risk of developing T2DM. The administration at an early stage by their antioxidant properties, which would enable them to scavenge the reactive oxygen species (ROS) induced by toxic amylin and inhibit the deposition of amylin aggregates in pancreatic islets and prevent their loss. T2DM is a chronic disease in which disease progression, amylin accumulation, and deposition $[65,66]$ require a prolonged time. Regular ingestion of chrysin, through diet or supplements, may protect against toxic amylin aggregation and the consequent death of $\beta$-cells.

The future therapeutic strategy involves avoidance of insoluble development of amylin, inhibition of oligomerization, and formation of fibrils, clearance of insoluble amylin peptides and, therefore, neurotoxicity prevention. Several scientists have shown the anti-amyloidogenic ability of several Phyto-compounds in light of the amylin hypothesis. One compound namely multimeric derivatives of quinacrine inhibit the formation of amylin fibrils [67]. Further research showed that carbazole-derivatives prevented the development of amylin fibrils in vivo [68]. It has been suggested that the compounds that bind to amylin peptides could be useful against formations of amylin fibrils.

\section{Conclusion}

Thus, by inhibiting amylin fibril aggregate formation under in vitro environment, chrysin demonstrated considerable anti-amylin potential, and this study gives a substantial lead that chrysin has the potential to be used as an anti-aggregation agent that could have disease-modifying effects in Alzheimer's disease. In addition, animal studies and pharmacokinetic studies are needed to validate in vivo models of the anti-amylin fibril aggregate potential.

\section{Abbreviations}

T2DM: Type-2 diabetes mellitus; RCSB: Research collaborator for structural bioinformatics; LGA: Lamarckian genetic algorithm; FBS: Fetal bovine serum; MTT: Dimethylthiazol-2-yl)-2,5-Diphenyltetrazolium bromide; ThT: Thioflavin T; ER: endoplasmic reticulum; PCA: protocatechuic acid.

\section{Acknowledgments}

The authors extend their appreciation to the Deanship of Scientific Research at King Saud University for funding this work through research group no (RG-1441-536).

\section{Availability of data and materials}

The data generated or analyzed in this article are online publicly available without request.

\section{Authors' contributions}

Abdullah A. Alkahtane, Hamzah A. Alghamdi, Bader Almutairi were performed the majority of the animal experiment and laboratory work; Mohd Muazzam Khan, Md Saquib Hasnain were acquired and analyzed the data; Mohamed M. Abdel-Daim, Wadha M. Alghamdi, Saad Alkahtani were involved in the conception and design of the study, data interpretation, and critically revised the manuscript.

\section{Competing Interests}

The authors have declared that no competing interest exists.

\section{References}

1. Przedborski S, Vila M, Jackson-Lewis V. Series Introduction: Neurodegeneration: What is it and where are we? J Clin Invest. 2003;111(1):3-10.

2. Owen JE, Veasey S. Impact of sleep disturbances on neurodegeneration: Insight from studies in animal models. Neurobiol Dis. 2020;104820.

3. Zhu X, Ji X, Shou Y, Huang Y, Hu Y, Wang H. Recent advances in understanding the mechanisms of PM2. 5-mediated neurodegenerative diseases. Toxicol Lett. 2020.

4. Chiti F, Dobson CM. Protein misfolding, functional amyloid, and human disease. Annu Rev Biochem. 2006;75:333-66.

5. Westermark P, Andersson A, Westermark GT. Islet amyloid polypeptide, islet amyloid, and diabetes mellitus. Physiol Rev. 2011;91(3):795-826.

6. Stridsberg M, Wilander E. Islet amyloid polypeptide (IAPP) a short review. Acta Oncol (Madr). 1991;30(4):451-6.

7. Mukherjee A, Morales-Scheihing D, Butler PC, Soto C. Type 2 diabetes as a protein misfolding disease. Trends Mol Med. 2015;21(7):439-49. 
8. Jaikaran ETAS, Clark A. Islet amyloid and type 2 diabetes: from molecular misfolding to islet pathophysiology. Biochim Biophys Acta (BBA)-Molecular Basis Dis. 2001;1537(3):179-203.

9. Bai Y, Tohda C, Zhu S, Hattori M, Komatsu K. Active components from Siberian ginseng (Eleutherococcus senticosus) for protection of amyloid $\beta$ (25-35)-induced neuritic atrophy in cultured rat cortical neurons. J Nat Med. 2011;65(3-4):417-23.

10. Montane J, Klimek-Abercrombie A, Potter KJ, Westwell-Roper C, Bruce Verchere C. Metabolic stress, IAPP and islet amyloid. Diabetes, Obes Metab. 2012;14:68-77.

11. Bram Y, Frydman-Marom A, Yanai I, Gilead S, Shaltiel-Karyo R, Amdursky N, et al. Apoptosis induced by islet amyloid polypeptide soluble oligomers is neutralized by diabetes-associated specific antibodies. Sci Rep. 2014;4(1):1-9.

12. Haass C, De Strooper B. The presenilins in Alzheimer's disease--proteolysis holds the key. Science (80- ). 1999;286(5441):916-9.

13. Nordberg A. PET imaging of amyloid in Alzheimer's disease. lancet Neurol. 2004;3(9):519-27.

14. Walsh DM, Klyubin I, Fadeeva J V, Cullen WK, Anwyl R, Wolfe MS, et al. Naturally secreted oligomers of amyloid $\beta$ protein potently inhibit hippocampal long-term potentiation in vivo. Nature. 2002;416(6880):535-9.

15. Gazit E. A possible role for $\Pi$-stacking in the self-assembly of amyloid fibrils. FASEB J. 2002;16(1):77-83.

16. Gazit E. Global analysis of tandem aromatic octapeptide repeats: The significance of the aromatic-glycine motif. Bioinformatics. 2002;18(6):880-3.

17. Soto C, Sigurdsson EM, Morelli L, Kumar RA, Castaño EM, Frangione B. $\beta$-sheet breaker peptides inhibit fibrillogenesis in a rat brain model of amyloidosis: implications for Alzheimer's therapy. Nat Med. 1998;4(7):822-6.

18. Ghosh AK, Kumaragurubaran N, Hong L, Koelsh G, Tang J. Memapsin 2 (beta-secretase) inhibitors: drug development. Curr Alzheimer Res. 2008;5(2):121-31.

19. Cao C, Lin X, Wahi MM, Jackson EA, Potter H. Successful adjuvant-free vaccination of $\mathrm{BALB} / \mathrm{c}$ mice with mutated amyloid $\beta$ peptides. BMC Neurosci. 2008;9(1):1-11

20. Youm JW, Jeon JH, Kim H, Kim YH, Ko K, Joung H, et al. Transgenic tomatoes expressing human beta-amyloid for use as a vaccine against Alzheimer's disease. Biotechnol Lett. 2008;30(10):1839-45.

21. Cheng Y, Feng Z, Zhang Q, Zhang J. Beneficial effects of melatonin in experimental models of Alzheimer disease. Acta Pharmacol Sin. 2006;27(2):129-39.

22. De Felice FG, Velasco PT, Lambert MP, Viola K, Fernandez SJ, Ferreira ST, et al. $A \beta$ oligomers induce neuronal oxidative stress through an N-methyl-Daspartate receptor-dependent mechanism that is blocked by the Alzheimer drug memantine. J Biol Chem. 2007;282(15):11590-601.

23. Tarasoff-Conway JM, Carare RO, Osorio RS, Glodzik L, Butler T, Fieremans E, et al. Clearance systems in the brain-implications for Alzheimer disease. Nat Rev Neurol. 2015;11(8):457.

24. Karran E, Mercken M, De Strooper B. The amyloid cascade hypothesis for Alzheimer's disease: an appraisal for the development of therapeutics. Nat Rev Drug Discov. 2011;10(9):698-712.

25. Serpell LC. Alzheimer's amyloid fibrils: structure and assembly. Biochim Biophys Acta (BBA)-Molecular Basis Dis. 2000;1502(1):16-30.

26. Mattson MP. Pathways towards and away from Alzheimer's disease. Nature. 2004;430(7000):631-9.

27. Manchali S, Murthy KNC, Patil BS. Crucial facts about health benefits of popular cruciferous vegetables. J Funct Foods. 2012;4(1):94-106.

28. Deng G-F, Lin X, Xu X-R, Gao L-L, Xie J-F, Li H-B. Antioxidant capacities and total phenolic contents of 56 vegetables. J Funct Foods. 2013;5(1):260-6.

29. Liu C-M, Ma J-Q, Liu S-S, Zheng G-H, Feng Z-J, Sun J-M. Proanthocyanidins improves lead-induced cognitive impairments by blocking endoplasmic reticulum stress and nuclear factor-kB-mediated inflammatory pathways in rats. Food Chem Toxicol. 2014;72:295-302.

30. Nabavi SF, Braidy N, Habtemariam S, Orhan IE, Daglia M, Manayi A, et al. Neuroprotective effects of chrysin: From chemistry to medicine. Neurochem Int. 2015;90:224-31

31. Lin L, Ni B, Lin H, Zhang M, Li X, Yin X, et al. Traditional usages, botany, phytochemistry, pharmacology and toxicology of Polygonum multiflorum Thunb.: a review. J Ethnopharmacol. 2015;159:158-83.

32. Nday CM, Halevas E, Jackson GE, Salifoglou A. Quercetin encapsulation in modified silica nanoparticles: potential use against $\mathrm{Cu}$ (II)-induced oxidative stress in neurodegeneration. J Inorg Biochem. 2015;145:51-64.

33. Ahmed ME, Khan MM, Javed H, Vaibhav K, Khan A, Tabassum R, et al. Amelioration of cognitive impairment and neurodegeneration by catechin hydrate in rat model of streptozotocin-induced experimental dementia of Alzheimer's type. Neurochem Int. 2013;62(4):492-501.

34. Zhang Q, Zhao JJ, Xu J, Feng F, Qu W. Medicinal uses, phytochemistry and pharmacology of the genus Uncaria. J Ethnopharmacol. 2015;173:48-80.

35. Ashafaq M, Raza SS, Khan MM, Ahmad A, Javed H, Ahmad ME, et al. Catechin hydrate ameliorates redox imbalance and limits inflammatory response in focal cerebral ischemia. Neurochem Res. 2012;37(8):1747-60.

36. Adedayo BC, Oboh G, Oyeleye SI, Ejakpovi II, Boligon AA, Athayde ML. Blanching alters the phenolic constituents and in vitro antioxidant and anticholinesterases properties of fireweed (Crassocephalum crepidioides). J Taibah Univ Med Sci. 2015;10(4):419-26.

37. Gomes A, Pimpão RC, Fortalezas S, Figueira I, Miguel C, Aguiar C, et al. Chemical characterization and bioactivity of phytochemicals from Iberian endemic Santolina semidentata and strategies for ex situ propagation. Ind Crops Prod. 2015;74:505-13.

38. Prakash D, Sudhandiran G. Dietary flavonoid fisetin regulates aluminium chloride-induced neuronal apoptosis in cortex and hippocampus of mice brain. J Nutr Biochem. 2015;26(12):1527-39.

39. Elbaz A, Carcaillon L, Kab S, Moisan F. Epidemiology of Parkinson's disease. Rev Neurol (Paris). 2016;172(1):14-26.

40. Angelopoulou E, Pyrgelis E-S, Piperi C. Neuroprotective potential of chrysin in Parkinson's disease: Molecular mechanisms and clinical implications. Neurochem Int. 2020;132:104612.

41. Naz S, Imran M, Rauf A, Orhan IE, Shariati MA, Shahbaz M, et al. Chrysin: Pharmacological and therapeutic properties. Life Sci. 2019;235:116797.

42. Maher P. The potential of flavonoids for the treatment of neurodegenerative diseases. Int J Mol Sci. 2019;20(12):3056.

43. Joshi V, Mishra R, Upadhyay A, Amanullah A, Poluri KM, Singh S, et al. Polyphenolic flavonoid (Myricetin) upregulated proteasomal degradation mechanisms: Eliminates neurodegenerative proteins aggregation. J Cell Physiol. 2019;234(11):20900-14.

44. Ayaz M, Sadiq A, Junaid M, Ullah F, Ovais M, Ullah I, et al. Flavonoids as prospective neuroprotectants and their therapeutic propensity in aging associated neurological disorders. Front Aging Neurosci. 2019;11.

45. Nanga RPR, Brender JR, Vivekanandan S, Ramamoorthy A. Structure and membrane orientation of IAPP in its natively amidated form at physiological $\mathrm{pH}$ in a membrane environment. Biochim Biophys Acta (BBA)-Biomembranes. 2011;1808(10):2337-42.

46. Morris GM, Goodsell DS, Halliday RS, Huey R, Hart WE, Belew RK, et al. Automated docking using a Lamarckian genetic algorithm and an empirical binding free energy function. J Comput Chem. 1998;19(14):1639-62.

47. López LC, Dos-Reis S, Espargaró A, Carrodeguas JA, Maddelein M-L, Ventura $\mathrm{S}$, et al. Discovery of novel inhibitors of amyloid $\beta$-peptide 1-42 aggregation. J Med Chem. 2012;55(22):9521-30.

48. López LC, Varea O, Navarro S, Carrodeguas JA, Sanchez de Groot N, Ventura $\mathrm{S}$, et al. Benzbromarone, quercetin, and folic acid inhibit amylin aggregation. Int J Mol Sci. 2016;17(6):964.

49. Riss T, Niles A, Moravec R, Karassina N, Vidugiriene J. Cytotoxicity assays: In vitro methods to measure dead cells. In: Assay Guidance Manual [Internet]. Eli Lilly \& Company and the National Center for Advancing Translational Sciences; 2019.

50. Chromy BA, Nowak RJ, Lambert MP, Viola KL, Chang L, Velasco PT, et al. Self-assembly of A $\beta 1-42$ into globular neurotoxins. Biochemistry. 2003;42(44):12749-60.

51. Hardy J, Selkoe DJ. The amyloid hypothesis of Alzheimer's disease: progress and problems on the road to therapeutics. Science (80- ). 2002;297(5580):353-6.

52. Hardy JA, Higgins GA. Alzheimer's disease: the amyloid cascade hypothesis. Science (80- ). 1992;256(5054):184-6.

53. Cohen FE, Kelly JW. Therapeutic approaches to protein-misfolding diseases. Nature. 2003;426(6968):905-9.

54. Glabe CG. Structural classification of toxic amyloid oligomers. J Biol Chem. 2008;283(44):29639-43

55. Campioni S, Mannini B, Zampagni M, Pensalfini A, Parrini C, Evangelisti E, et al. A causative link between the structure of aberrant protein oligomers and their toxicity. Nat Chem Biol. 2010;6(2):140-7.

56. Wang Y, Lv Y, Jin L, Liang G. Revealing the Mechanism of EGCG, Genistein, Rutin, Quercetin, and Silibinin Against hIAPP Aggregation via Computational Simulations. Interdiscip Sci Comput Life Sci. 2020;12(1):59-68.

57. Noor H, Cao P, Raleigh DP. Morin hydrate inhibits amyloid formation by islet amyloid polypeptide and disaggregates amyloid fibers. Protein Sci. 2012;21(3):373-82

58. Adams M, Gmünder F, Hamburger M. Plants traditionally used in age related brain disorders - a survey of ethnobotanical literature. J Ethnopharmacol. 2007;113(3):363-81.

59. Rashno M, Sarkaki A, Farbood $Y$, Rashno M, Khorsandi L, Naseri MKG, et al. Therapeutic effects of chrysin in a rat model of traumatic brain injury: A behavioral, biochemical, and histological study. Life Sci. 2019;228:285-94.

60. Knowles TPI, Vendruscolo M, Dobson CM. The amyloid state and its association with protein misfolding diseases. Nat Rev Mol cell Biol. 2014;15(6):384-96.

61. Eisenberg D, Jucker M. The amyloid state of proteins in human diseases. Cell. 2012;148(6):1188-203.

62. Amiri M, Braidy N, Aminzadeh M. Protective Effects of Fibroblast Growth Factor 21 against Amyloid-Beta 1-42-Induced Toxicity in SH-SY5Y Cells. Neurotox Res. 2018;34(3):574-83.

63. Zuo L, Hemmelgarn BT, Chuang C-C, Best TM. The role of oxidative stress-induced epigenetic alterations in amyloid- $\beta$ production in Alzheimer's disease. Oxid Med Cell Longev. 2015;2015.

64. Azzam SK, Jang H, Choi MC, Alsafar H, Lukman S, Lee S. Inhibition of human amylin aggregation and cellular toxicity by lipoic acid and ascorbic acid. Mol Pharm. 2018;15(6):2098-106

65. Cheng B, Liu X, Gong $\mathrm{H}$, Huang L, Chen $\mathrm{H}$, Zhang X, et al. Coffee components inhibit amyloid formation of human islet amyloid polypeptide in vitro: possible link between coffee consumption and diabetes mellitus. J Agric Food Chem. 2011;59(24):13147-55.

66. Härd T, Lendel C. Inhibition of amyloid formation. J Mol Biol. 2012;421(45):441-65. 
67. Dolphin GT, Chierici S, Ouberai M, Dumy P, Garcia J. A Multimeric Quinacrine Conjugate as a Potential Inhibitor of Alzheimer's $\beta$-Amyloid Fibril Formation. Chembiochem. 2008;9(6):952-63.

68. Saengkhae C, Salerno M, Adès D, Siove A, Le Moyec L, Migonney V, et al. Ability of carbazole salts, inhibitors of Alzheimer $\beta$-amyloid fibril formation, to cross cellular membranes. Eur J Pharmacol. 2007;559(2-3):124-31. 